\title{
Associations of snoring frequency and intensity in pregnancy with time-to-delivery
}

\author{
Galit Levi Dunietz $^{1}$ (D) | Kerby Shedden ${ }^{2}$ | Enrique F. Schisterman ${ }^{3}$ | \\ Lynda D. Lisabeth $^{4}$ | Marjorie C. Treadwell ${ }^{5}$ | Louise M. O'Brien ${ }^{1,5}$
}

${ }^{1}$ Department of Neurology, Sleep Disorders Center, University of Michigan, Ann Arbor, Michigan

${ }^{2}$ Department of Statistics, University of Michigan, Ann Arbor, Michigan

${ }^{3}$ Division of Intramural Population Health Research, Eunice Kennedy Shriver National Institute of Child Health and Human Development, National Institute of Health, Rockville, Maryland

${ }^{4}$ Department of Epidemiology, School of Public Health, University of Michigan, Ann Arbor, Michigan

${ }^{5}$ Department of Obstetrics and Gynecology, University of Michigan, Ann Arbor, Michigan

\section{Correspondence}

Galit Levi Dunietz, Sleep Disorders Center, University of Michigan, Ann Arbor, MI.

Email: gldt@med.umich.edu

\section{Funding information}

GLD was supported by a T32 Grant from the National Institute of Neurological Disorders and Stroke (NIH/NINDS T32 NS007222) and by a grant from Eunice Kennedy Shriver National Institute of Child Health and Human Development (NIH/NICHD F32 HD091938). LMO was supported by the Gene and Tubie Gilmore Fund for Sleep Research, by the University of Michigan Institute for Clinical and Health Research (MICHR) grant UL1TR000433, by MICHR seed pilot grant F021024, and by the National Heart, Lung, and Blood Institute (R21 HL089918). During the course of this study, Dr. O'Brien was also supported by a career grant from the National Heart, Lung, and Blood Institute (K23 HL095739) and in part by R21 HL087819. None of the funding sources had any role in study design; collection, analysis, interpretation of data; writing of the report; or the decision to submit the report for publication.

\begin{abstract}
Background: Sleep-disordered breathing (SDB) is linked to adverse pregnancy outcomes. However, little is known about the association of SDB with timing of delivery. We examined the association of snoring frequency, a key SDB marker, and snoring intensity, a correlate of SDB severity, with time-to-delivery among a cohort of pregnant women.
\end{abstract}

Methods: In this prospective cohort study, 1483 third trimester pregnant women were recruited from the University of Michigan prenatal clinics. Women completed a questionnaire about their sleep, and demographic and pregnancy information was abstracted from medical charts. After exclusion of those with hypertension or diabetes, 954 women were classified into two groups by their snoring onset timing, chronic or pregnancy-onset. Within each of these groups, women were divided into four groups based on their snoring frequency and intensity: non-snorers; infrequentquiet; frequent-quiet; or frequent-loud snorers. Cox proportional hazard regression models were used to investigate the association between snoring frequency and intensity and time-to-delivery, adjusting for maternal characteristics.

Results: Chronic snoring was reported by half of the pregnant women, and of those, $7 \%$ were frequent-loud snorers. Deliveries before 38 weeks' gestation are completed occurred among $25 \%$ of women with chronic, frequent-loud snoring. Compared with prepregnancy non-snorers, women with chronic frequent-loud snoring had an increased hazard ratio for delivery (adjusted hazard ratio 1.60, 95\% confidence interval 1.04, 2.45). Conclusions: Snoring frequency and intensity is associated with time-to-delivery in women absent of hypertension or diabetes. Frequent-loud snoring may have a clinical utility to identify otherwise low-risk women who are likely to deliver earlier.

\section{KEYWORDS}

frequent snoring, gestational age at delivery, habitual snoring, loud snoring, preterm birth, sleep-disordered breathing, time-to-delivery 


\section{1 | INTRODUCTION}

Preterm deliveries (PTD), before the completion of 37 weeks' gestation, represent $11 \%$ of total US births, ${ }^{1}$ and are major contributors to infant morbidity and mortality. ${ }^{2,3}$ Multiple risk factors have been linked to earlier deliveries, including infections, chronic maternal conditions, obstetric complications, behavioural and sociodemographic factors. ${ }^{4-6}$ Sleep disturbances have also been related to adverse birth outcomes. ${ }^{7-9}$ In particular, frequent snoring, the hallmark symptom of sleep-disordered breathing (SDB) and its severe formobstructive sleep apnoea (OSA)-have been independently associated with several key adverse pregnancy outcomes: hypertensive disorders of pregnancy; gestational diabetes; caesarean section; and small newborn size. ${ }^{10-13}$ However, inconsistent data on the association of SDB and PTD or mean gestational age at delivery suggest a positive ${ }^{14,15}$ or no association. ${ }^{16-18}$ Similarly, mixed findings have been reported with objectively measured OSA. ${ }^{19,20}$ Diverse exposure and outcome definitions, sample size, and control of known confounders, that is hypertension and diabetes, likely drive the inconsistencies.

Snoring is typically defined by its frequency and few studies consider intensity. In non-pregnant populations, snoring intensity has been correlated with OSA severity, measured with an overnight polysomnography, in a dose-response manner. ${ }^{21-23}$ Little consideration has been given to snoring intensity in pregnancy. Furthermore, despite the inherent temporal property of gestational age at delivery, prior studies have rarely framed deliveries as time-to-event outcomes. ${ }^{24}$. In the light of a growing body of research on key developmental processes that occur between 37 and 39 completed weeks' gestation, ${ }^{25,26}$ the American College of Obstetricians and Gynecologists (ACOG) has redefined full-term as 39-40 completed weeks' gestation and deliveries at 37-38 completed weeks' gestation are considered early-term. ${ }^{27}$ Using time-to-event approach, rather than a dichotomy of full-term vs preterm, provides week-specific risk of delivery along the gestational age continuum, a clinically useful information with important implications. We therefore examined the association between snoring frequency and intensity and time-todelivery in a large prospective cohort of pregnant women without hypertension or diabetes, key pregnancy co-morbidities, linked to SDB. We hypothesised that snoring intensity will be positively associated with earlier deliveries.

\section{2 | METHODS}

\section{1 | Study population}

This secondary analysis utilised prospective data of pregnant women recruited between March 2008 and December 2010 from prenatal clinics within the University of Michigan, a large tertiary medical centre. ${ }^{12}$ Inclusion criteria were maternal age $\geq 18$ years old, gestational week $\geq 28$ and a singleton pregnancy. Of the women approached, $84 \%$ consented and enrolled in the study. To control for pregnancy co-morbidities that confound the association of SDB and time-to-delivery, we restricted this study to women without a diagnosis of hypertension or diabetes. The following exclusion criteria were used: (a) pre-pregnancy hypertension or hypertensive disorders of pregnancy; and (b) Pre-pregnancy diabetes or gestational diabetes (see Figure 1). Women reported their snoring characteristics and demographic data via questionnaire (see below). Maternal and pregnancy outcomes were abstracted from their medical charts. All women provided written informed consent. The study obtained approval from the University of Michigan Institutional Review Board.

\subsection{Gestational age at delivery}

Gestational age at delivery, based on third trimester best obstetric estimate, was abstracted from medical charts and analysed as a time-to-event outcome. Deliveries were classified as vaginal, planned caesarean section or emergency caesarean section. Elective caesarean section deliveries were censored if a woman had undergone a previous abdominal surgery, a strong predictor of a repeat surgical delivery. Women were followed from the time of enrolment until they delivered or were censored.

\section{3 | Snoring characteristics}

Data on snoring frequency and intensity were collected via questionnaire during the third trimester, as by the third trimester, snoring has been developed and prevalent among at least a fifth of pregnant women. ${ }^{28}$ Specifically, women were asked about the frequency of snoring: (a) almost daily, 3-4 times per week, 1-2 times per week, 1-2 times per month, or never; and (b) snoring intensity: very quiet, quiet, moderate or variable, loud or very loud. Prior studies have demonstrated that the timing of frequent snoring has a differential impact

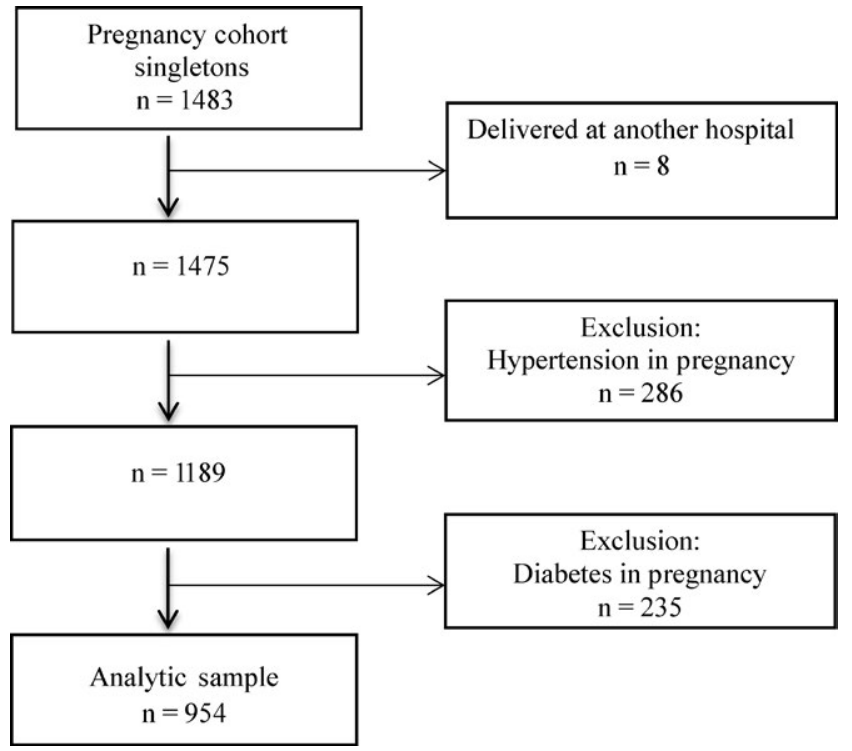

FIGURE 1 Flow chart of participants in the sleep pregnancy cohort: 2008-2010 
on maternal and foetal outcomes, with chronic snoring driving the relationship with foetal growth restriction. ${ }^{29}$ Thus, women were also asked about the timing of their snoring onset in relation to the pregnancy, whether chronic (began before pregnancy) or pregnancyonset. Information about timing of snoring was used to create two strata for chronic, pre-pregnancy and pregnancy-onset snorers. Within each strata and based on their pre-pregnancy snoring profile, women were classified into the four study groups: (a) Non-snorers, (b) Infrequent-quiet snorers, (c) Frequent-quiet snorers, and (c) Frequent-loud snorers. Non-snorers in the pre-pregnancy stratum ( $n=473$ ) were further classified into the four study groups according to their pregnancy snoring status (Figure S1). Two women that reported infrequent-loud snoring were included as frequent-loud snoring, as their baseline characteristics were similar to women in this group. Women with missing snoring information were excluded from the analysis ( $<1 \%$ of the total sample).

\section{4 | Covariates}

We used a directed acyclic graph to guide covariate selection in the adjusted Cox regression models (Figure S2). Baseline body mass index (BMI/continuous) recorded during the initial prenatal visit in the first trimester was obtained from medical charts. Maternal race, education, parity, smoking (yes/no) and mode of delivery (vaginal, planned or emergency caesarean section) were abstracted from medical charts and included in the adjusted Cox regression models.

\section{5 | Statistical analyses}

Descriptive statistics, chi-square, and linear regression tests were used to compare the distributions of sociodemographic, maternal, pregnancy, and delivery characteristics among women classified by their snoring frequency and intensity and by the timing of their snoring onset. We then examined the associations of snoring frequency and intensity among women in groups in the chronic or pregnancyonset strata.

We investigated the association of snoring frequency and intensity with time-to-delivery among a cohort of pregnant women, free of hypertensive disorders and diabetes, common disorders known to be associated both with SDB and earlier deliveries. This approach allows the investigation of snoring influence on timing of deliveries in an otherwise healthy pregnant women without the presence of these key confounding variables. Women with a scheduled caesarean delivery due to a prior abdominal surgery were excluded as they did not follow a natural time-to-delivery process. We also censored women who delivered after the completion of 42 weeks' gestation as post-term deliveries are associated with negative maternal, foetal and neonatal consequences. ${ }^{30}$ Kaplan-Meier methods were applied to estimate the cumulative delivery rate along the third trimester among pregnant women classified by snoring frequency and intensity and timing of snoring onset. The probability of delivery prior to 37 completed weeks' gestation was estimated in women with chronic frequent-loud snoring and non-snores. We used the Log-rank chi-squared test to compare the Kaplan-Meier survival curves along the third trimester of women in each group. To evaluate the association of time-to-delivery and snoring frequency and intensity, we fitted two Cox proportional hazard regression models among pregnant women with chronic or pregnancy-onset snoring, respectively. In these models, we controlled for pregnancy characteristics. The Cox regression analyses produce hazard ratio that represents the relative likelihood of delivery along the gestational age for women in each snoring stratum compared with non-snorers and those who did not deliver at that time. All analyses were conducted with SAS 9.4 (Cary, NC).

\section{3 | RESULTS}

A total of 1483 pregnant women between 28 to 40 weeks' gestation were recruited from prenatal clinics. After exclusion of eight women who were lost to follow-up (delivered elsewhere) and 521 women with either hypertensive disorders of pregnancy, diabetes or both, the resulting cohort comprised of 954 non-hypertensive and nondiabetic pregnant women (Figure 1).

\section{1 | Chronic snoring}

In the cohort of 946 pregnant women in the pre-pregnancy stratum, half were non-snorers, while $41 \%$ and $5 \%$ were chronic, infrequentquiet or frequent-quiet snorers, respectively. Of the 473 women with chronic snoring, $7 \%$ were frequent-loud snorers. Similar distributions of maternal age, race and parity were observed across snoring frequency and intensity groups (Table 1). However, attained education, smoking, mean gestational age at delivery, mean baseline $\mathrm{BMI}$, and mode of delivery were associated with snoring frequency and intensity (Table 1).

Figure 2 represents the Kaplan-Meier plot of the cumulative delivery incidence among the four groups of pregnant women in the chronic snoring stratum. For these women, there were no differences among the median gestational week at delivery; 39.7, 39.9, 39.7 and 39.6 weeks for non-snorers, infrequent-quiet, frequentquiet and frequent-loud snorers, respectively. However, the first quartile (25\%) gestational week at delivery was 38.7, 38.9, 38.7 and 38.1 weeks for non-snorers, infrequent-quiet, frequent-quiet and frequent-loud pregnant snorers. The Kaplan-Meier curves of infrequent-quiet, frequent-quiet, frequent-loud, and non-snorers were different $(P<0.05)$. We estimated the positive predictive value for chronic, frequent-loud snorers and for non-snorers. The probability of preterm delivery (<37 weeks gestation) was $24 \%$ among frequent-loud snorers vs $10 \%$ in non-snorers. In multivariable Cox proportional hazard regression models for chronic snorers, snoring frequency and intensity, maternal education, parity, smoking and baseline BMI were associated with time-to-delivery, but race was not (Table 2). Compared with non-snorers, the hazard ratio for delivery, adjusted for pregnancy characteristics, 
TAB LE 1 Demographic characteristics of pregnant women with chronic and pregnancy-onset snoring by its frequency and intensity

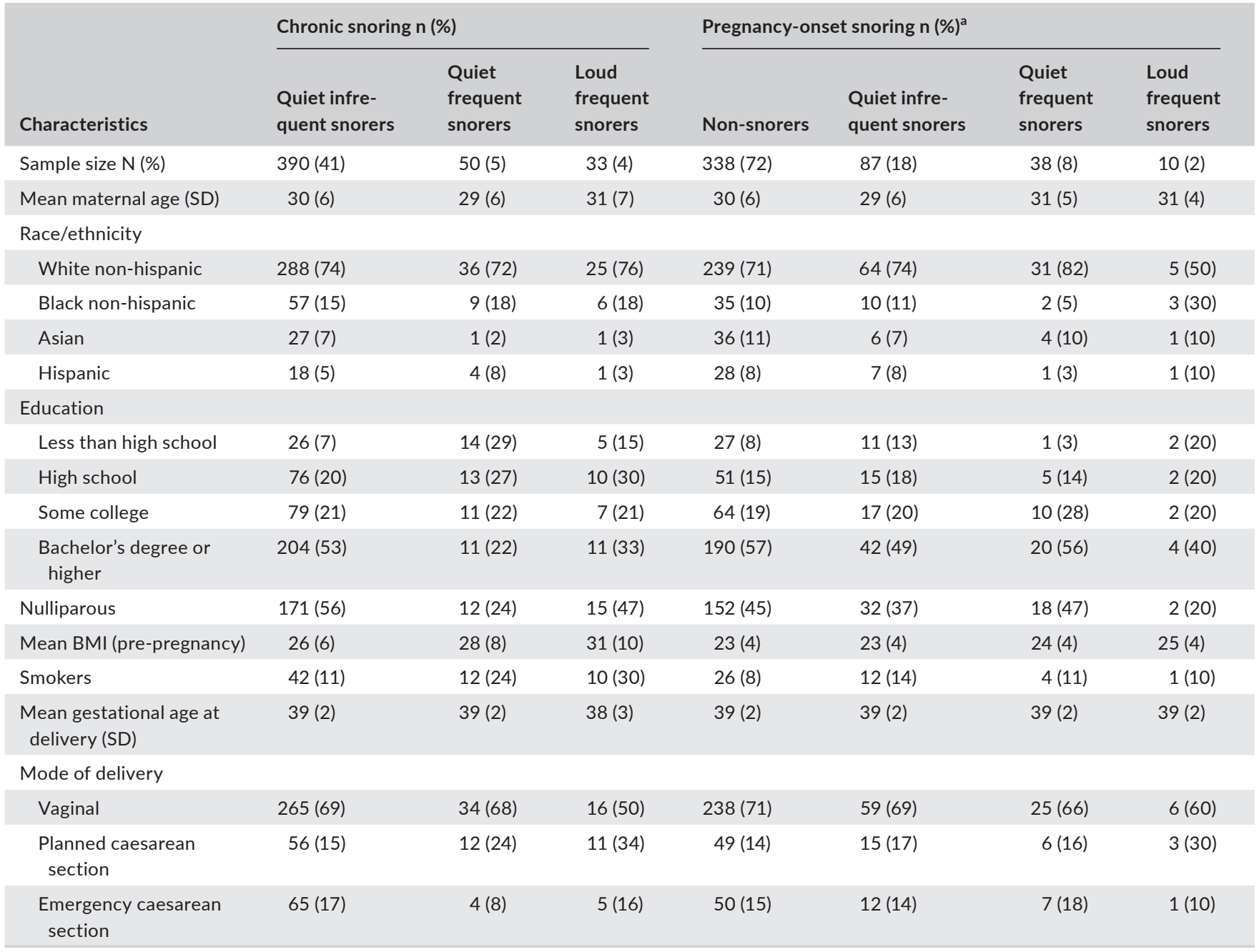

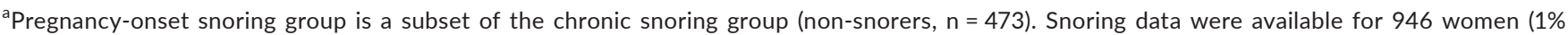
missing).

FIGURE 2 Kaplan-Meier survival curves: chronic sleep-disordered breathing and time-to-delivery in a cohort of women without diabetes or hypertension classified by snoring frequency and intensity

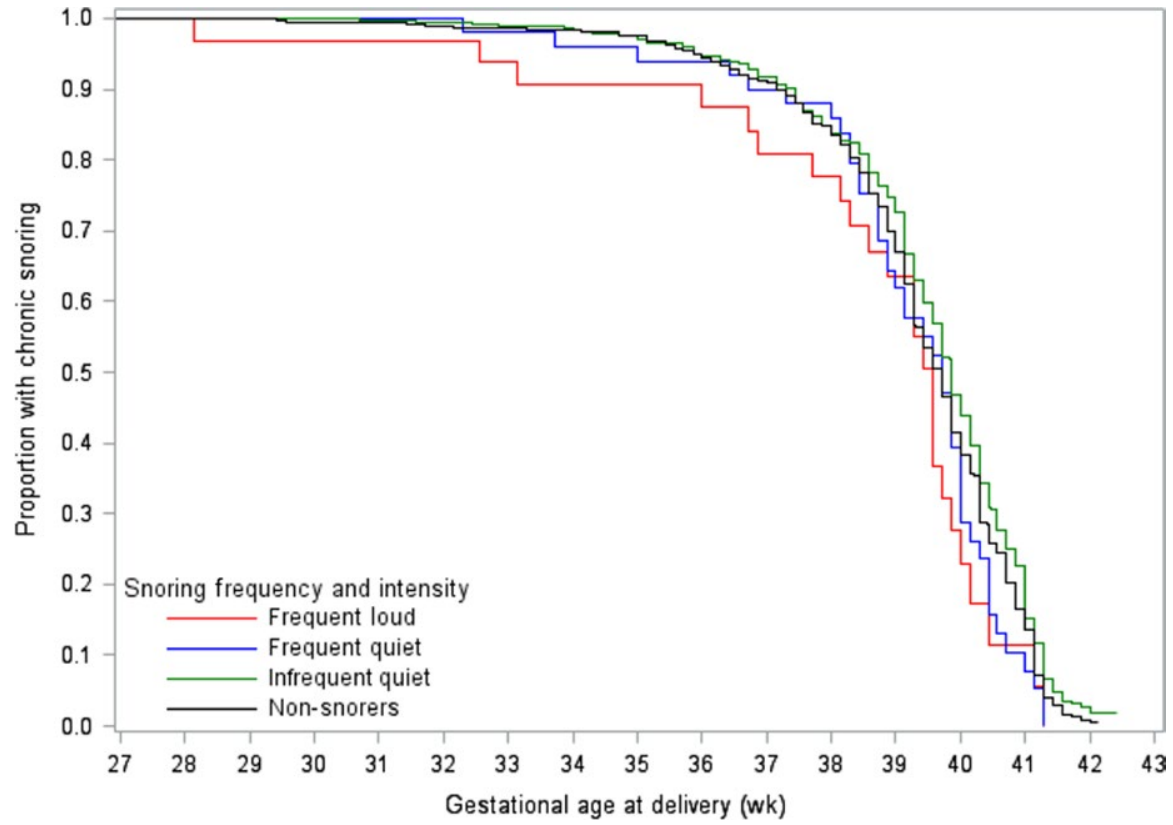




\begin{tabular}{|c|c|c|}
\hline $\begin{array}{l}\text { Maternal and pregnancy } \\
\text { characteristics }\end{array}$ & $\begin{array}{l}\text { Model 1: unadjusted hazard } \\
\text { ratio }(95 \% \mathrm{Cl})\end{array}$ & $\begin{array}{l}\text { Model 2: adjusted } \\
\text { hazard ratio }(95 \% \mathrm{Cl})\end{array}$ \\
\hline \multicolumn{3}{|l|}{ Snoring frequency intensity } \\
\hline Non-snorers & 1.00 (Reference) & 1.00 (Reference) \\
\hline Infrequent-quiet snorers & $0.81(0.70,0.94)$ & $0.88(0.76,1.03)$ \\
\hline Frequent-quiet snorers & $1.03(0.75,1.42)$ & $0.96(0.68,1.37)$ \\
\hline Loud frequent snorers & $1.30(0.86,1.97)$ & $1.60(1.04,2.46)$ \\
\hline \multicolumn{3}{|l|}{ Race/ethnicity } \\
\hline White non-hispanic & 1.00 (Reference) & 1.00 (Reference) \\
\hline Black non-hispanic & $1.19(0.97,1.47)$ & $1.06(0.85,1.33)$ \\
\hline Asian & $1.23(0.96,1.57)$ & $1.22(0.94,1.59)$ \\
\hline Hispanic & $1.01(0.76,1.34)$ & $0.85(0.63,1.14)$ \\
\hline \multicolumn{3}{|l|}{ Education } \\
\hline Less than high school & $1.73(1.35,2.21)$ & $1.66(1.26,2.20)$ \\
\hline High school & $1.19(0.99,1.44)$ & $1.24(1.01,1.53)$ \\
\hline Some college & $1.14(0.95,1.37)$ & $1.18(0.97,1.43)$ \\
\hline Bachelor's degree or higher & 1.00 (Reference) & 1.00 (Reference) \\
\hline \multicolumn{3}{|l|}{ Parity } \\
\hline 0 & 1.00 (Reference) & 1.00 (Reference) \\
\hline$\geq 1$ & $1.30(1.13,1.49)$ & $1.35(1.17,1.57)$ \\
\hline \multicolumn{3}{|l|}{ Smoking } \\
\hline Yes & $1.33(1.07,1.65)$ & $1.21(0.95,1.53)$ \\
\hline No & 1.00 (Reference) & 1.00 (Reference) \\
\hline Baseline pregnancy BMI & $0.98(0.97,0.99)$ & $0.97(0.96,0.99)$ \\
\hline
\end{tabular}

BMI, Body mass index; $\mathrm{Cl}$, confidence interval; Model 1: unadjusted; Model 2: adjusted for maternal race/ethnicity, education, parity, smoking and baseline pregnancy BMI.

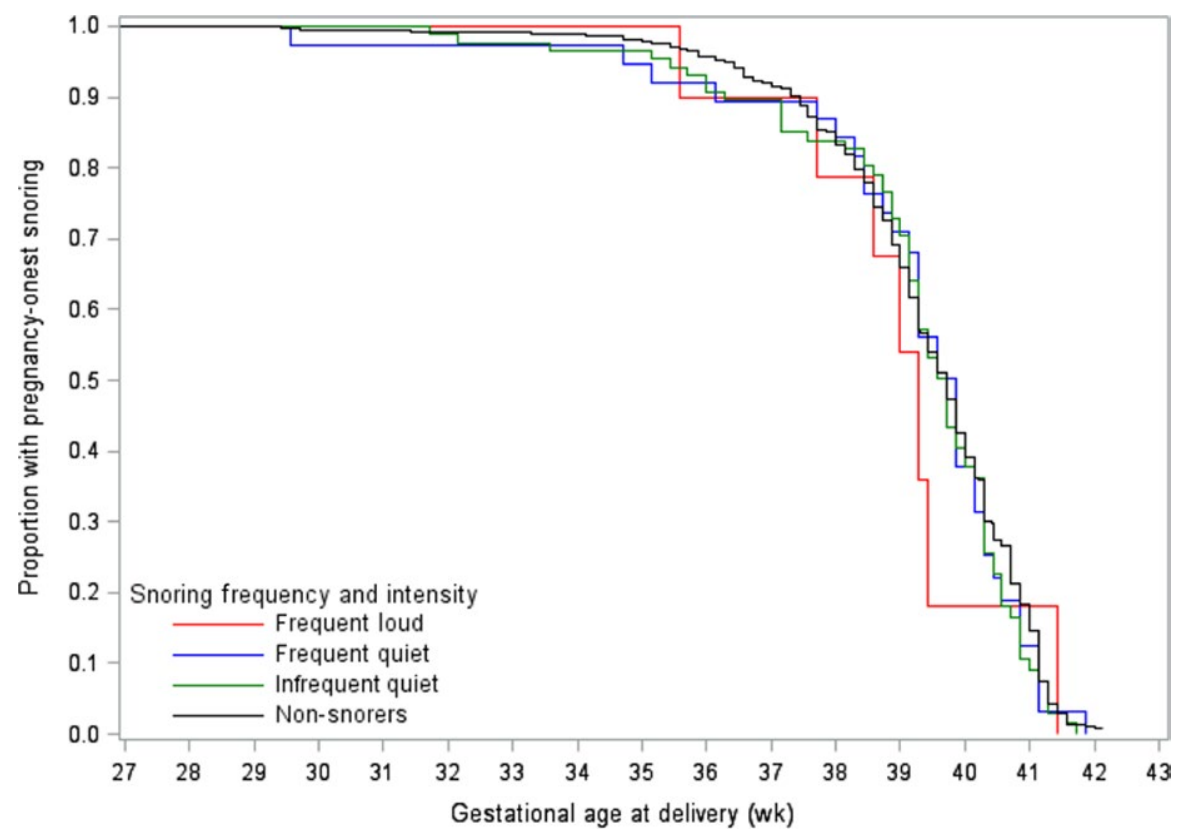

TABLE 2 Hazard ratios of chronic snoring frequency and intensity and time-to-delivery among a cohort of pregnant women without diabetes or hypertension
FIGURE 3 Kaplan-Meier survival curves: pregnancy-onset sleep-disordered breathing and time-to-delivery in a cohort of women without diabetes or hypertension classified by snoring frequency and intensity was increased among frequent-loud snorers $[\mathrm{HR}=1.60(95 \% \mathrm{Cl}$ $1.04,2.45)]$, but not for infrequent-quiet snorers [HR $=0.88(95 \%$ $\mathrm{Cl} 0.76,1.02)]$ or frequent-quiet snores $[\mathrm{HR}=0.96(95 \% \mathrm{Cl} 0.68$, 1.37)].

\section{2 | Pregnancy-onset snoring}

Pregnancy snoring was experienced by $28 \%$ of the women $(n=135)$ and was mostly developed during the second trimester. Among 
these snorers, the majority were infrequent-quiet (64\%), more than a quarter were frequent-quiet, and $7 \%$ were frequent-loud snorers (Table 1). There were no associations between maternal and pregnancy characteristics and snoring frequency and intensity (Table 1).

The Kaplan-Meier survival curves were similar across pregnancyonset snorers and non-snorers $(P=0.9)$. The median gestational week at delivery was 39.7 for non-snorers or infrequent-quiet snorers, 39.9 for frequent-quiet snorers, and 39.3 for women with frequent-loud snoring. A quarter of women, in all study groups, delivered before 39 completed weeks' gestation (Figure 3).

In multivariable Cox proportional hazard regression models for pregnancy-onset snorers, snoring frequency and intensity was not associated with time-to-delivery. Adjusted for pregnancy characteristics, the hazard ratios for delivery were similar among all snorers compared with non-snores; infrequent-quiet snorers $[H R=1.29$ $(95 \% \mathrm{Cl} 0.99,1.67)]$; frequent-quiet snores [HR $=1.41(95 \% \mathrm{Cl} 0.97$, 2.04)]; and frequent-loud snorers [HR $=1.59(95 \% \mathrm{Cl} 0.72,3.51)]$.

\section{4 | COMMENT}

\section{1 | Principal findings}

In this large cohort of non-hypertensive and non-diabetic pregnant women, we have shown that chronic, frequent-loud snoring is associated with increased hazard for earlier deliveries. Women with infrequent-quiet, or frequent-quiet snoring had a similar delivery hazard as non-snorers. Notably, a fifth of chronic, frequent-loud snorers-absent of key pregnancy co-morbidities-delivered before the completion of 37 weeks' gestation compared with a tenth of the non-snorers. The finding that chronic, but not pregnancy-onset, snoring is associated with time-to-delivery in women without key co-morbidities, emphasise the importance of screening not only for frequency of snoring but also its intensity and chronicity in otherwise healthy women.

\subsection{Strengths of the study}

One of the major strengths of this work is the ability to determine the association of maternal snoring on time-to-delivery by exclusion of women with hypertensive disorders of pregnancy and gestational diabetes, as these have been independently associated with both SDB and earlier deliveries. ${ }^{12,19}$ The large sample size of this cohort provided sufficient power to exclude women with these relatively common pregnancy conditions. Our findings suggest that even among women without these key co-morbidities, chronic frequentloud snoring still posits a risk of earlier deliveries.

Another strength of this study is our original approach that analyses deliveries as a time-to-event outcome with survival analysis, rather than previously used statistical methods, that is linear or logistic regressions. Despite the inherent property of time in pregnancy and delivery events, time-to-event analysis has been rarely used in this context. ${ }^{24}$ Earlier deliveries are often associated with neonatal morbidity and mortality corresponding to the gestational week at delivery. In this analysis, the outcome of interest, delivery events, are observed among all women in the third trimester, with two purposes: (a) estimating the probability that a woman will deliver (or not) by a given gestational week, and (b) comparing timeto-delivery among study groups. With the Kaplan-Meier analysis, we estimated the probability of delivery during or before both the preterm and early-term gestational age range, which demonstrated a higher frequency of delivery prior to both 37 and 39 completed weeks' gestation among chronic, frequent-loud snoring women compared with controls.

\subsection{Limitations of the data}

This study is not without limitations. Recruitment of pregnant women during the third trimester prevented inclusion of women who have already delivered and analyses of deliveries before the completion of 28 weeks' gestation. Nonetheless, less than $1 \%$ of deliveries in the United States occur prior to 28 completed weeks' gestation, ${ }^{1}$ thus, we believe that the distribution of gestational ages at delivery in our study is representative of PTD. Another potential limitation is related to the self-reporting of snoring characteristics that may introduce information bias. However, there are several advantages to using subjective snoring measures in this study: (a) self-reported snoring frequency was strongly and reliably associated with a diagnosis of OSA obtained by an in-laboratory polysomnography (PSG); ;1,32 (b) symptoms can predict outcomes when objective measures fail to do so; ${ }^{33}$ and (c) symptom-based screening is common practice in clinical settings and large-scale investigations as collection of objective data through sleep studies is not logistically nor financially feasible. In addition, to date, there are no validated screening tools for SDB in pregnancy. Most SDB scales emphasise weight, which in pregnancy will be necessarily high, while several scales rely on hypertensive status, which we restricted for in the current study, or gender, irrelevant to a study of pregnant women. Whether the presence of hypertension or diabetes confounds or mediates the SDB-early deliveries association is still unclear. However, as our data did not support indirect pathways between snoring and earlier deliveries, through hypertensive disorders of pregnancy and gestational diabetes, we considered those pregnancy disorders as confounders. Finally, small subgroups size in the pregnancy-onset snoring stratum may have limited our ability to detect significant results. However, the size of the effect estimates in this stratum suggests possible associations between snoring characteristics and timing of delivery. To further examine these associations, we conducted sensitivity analyses within larger groups in the pregnancy-onset stratum. Specifically, we collapsed women with pregnancy-onset snoring into three groups by the frequency or intensity of their snoring and ran two separate regression models. We first grouped women by snoring intensity-non-snorers, quiet snores, loud snorers, and later by snoring frequency-non-snorers, infrequent snores, and frequent 
snorers. Results from the first analysis suggested an increased HR for women in the quiet group (frequent + infrequent snorers) compared with controls $(H R=1.32,95 \% \mathrm{Cl} 1.05,1.66)$. Similarly, the second analysis produced an increased HR for women in the frequent (quiet + loud) group compared with controls ( $H R=1.44,95 \%$ $\mathrm{Cl}$ 1.02, 2.02). These sensitivity analyses associated both snoring characteristics-frequency and intensity-with the timing of delivery and supports additional larger studies.

\section{4 | Interpretation}

The role of SDB in the timing of delivery has been investigated in several studies with mixed findings, likely driven by study design heterogeneity, for example SDB and PTD definitions (snoring vs objective measures and thresholds of earlier deliveries), sample size, control for third variables, and statistical approaches. Frequent snoring has been inconsistently linked to PTD or mean gestational age at delivery. ${ }^{14-16,18}$ In non-pregnant populations, snoring intensity, defined as loud or as disruptive to others, has been shown to characterise the severity of disease, such that loud snoring correlates to objective measures of OSA severity. ${ }^{21-23,34,35}$ Surprisingly, snoring intensity has been rarely measured in pregnancy. In a descriptive study of sleep disturbances in pregnancy among 195 Chinese women, an increased prevalence of moderate-severe snoring intensity has been observed in women with a BMI $\geq 25$ compared with those with lower BMIs. ${ }^{36}$ A US-based cohort study with 1153 pregnant women found similar PTD rates among women with loud snoring, often-snoring, and non-snorers. ${ }^{17}$ However, neither of these studies has considered the timing of the snoring, which we have previously shown to be important in the association with pregnancy outcomes. ${ }^{12,29}$ Furthermore, although snoring intensity per se was not measured, self-report of witnessed apnoea or gasping as a marker of more severe SDB has been associated with approximately two-fold PTD odds. ${ }^{14}$ These data suggest that both frequency and intensity of snoring should be considered together when investigating associations of snoring and poor pregnancy outcomes.

In adjusted models, baseline maternal BMI was associated with longer time-to-delivery suggesting that as maternal BMI increases, the likelihood of early delivery decreases. This result is in contrast to the reported link between preterm birth and excessive maternal weight, ${ }^{4}$ but may be explained by the absence of hypertensive and diabetic women. Therefore, the obese women in this cohort may be "metabolically healthy obese" and their weight would not increase their risk for earlier delivery.

Potential mechanisms that link maternal sleep to adverse delivery outcomes may include inflammatory cascades and placental dysfunction. Inflammation, oxidative stress, and endothelial dysfunction are all implicated not only in SDB but also in adverse pregnancy outcomes. ${ }^{37,38}$ Disturbed sleep during early pregnancysuch as occurs in chronic snorers-likely contributes to an increased inflammatory response that could disrupt the normal remodelling of maternal blood vessels that perfuse the placenta. ${ }^{39}$ Placental insufficiency-due to uteroplacental hypoperfusion-could then occur, ${ }^{40}$ leading to a higher risk of earlier delivery. ${ }^{41}$

\section{5 | CONCLUSIONS}

Women with chronic frequent-loud snoring, absent of key comorbidities, have an increased hazard for earlier deliveries. These findings illustrate that snoring frequency and intensity is associated with the timing of delivery in women without hypertension or diabetes. Frequent-loud snoring may be a useful to identify otherwise low-risk women who are likely to deliver earlier

\section{ACKNOWLEDGEMENTS}

The authors wish to thank the women who participated in this study.

\section{CONFLICT OF INTEREST}

Dr. O'Brien has received equipment support from Philips Respironics Inc and Itamar Medical. All other authors did not report any potential conflict of interest.

\section{ETHICS APPROVAL}

This study obtained approval from the Institutional Review Board at the University of Michigan. All women provided written informed consent.

\section{ORCID}

Galit Levi Dunietz iD http://orcid.org/0000-0002-7240-4923

\section{REFERENCES}

1. Martin JA, Hamilton BE, Osterman M, Curtin SC, Matthews T. Births: final data for 2013. Natl Vital Stat Rep. 2015;64:1-65.

2. Kramer MS, Demissie K, Yang H, Platt RW, Sauvé R, Liston R. The contribution of mild and moderate preterm birth to infant mortality. JAMA. 2000;284:843-849.

3. Ananth CV, Goldenberg RL, Friedman AM, Vintzileos AM. Association of temporal changes in gestational age with perinatal mortality in the United States, 2007-2015. JAMA Pediatr. 2018;172:627-634.

4. Goldenberg RL, Culhane JF, lams JD, Romero R. Epidemiology and causes of preterm birth. Lancet. 2008;371:75-84.

5. Heaman M, Kingston D, Chalmers B, Sauve R, Lee L, Young D. Risk factors for preterm birth and small-for-gestational-age births among Canadian women. Paediatr Perinat Epidemiol. 2013;27:54-61.

6. Shaw GM, Wise PH, Mayo J, et al. Maternal prepregnancy body mass index and risk of spontaneous preterm birth. Paediatr Perinat Epidemiol. 2014;28:302-311.

7. Sharma S, Nehra A, Sinha S, et al. Sleep disorders in pregnancy and their association with pregnancy outcomes: a prospective observational study. Sleep Breath. 2016;20:87-93. 
8. Lee KA, DeJoseph JF. Sleep disturbances, vitality, and fatigue among a select group of employed childbearing women. Birth. 1992;19:208-213.

9. Facco FL, Liu CS, Cabello AA, Kick A, Grobman WA, Zee PC. Sleepdisordered breathing: a risk factor for adverse pregnancy outcomes? Am J Perinatol. 2012;29:277-282.

10. Facco FL, Grobman WA, Kramer J, Ho KH, Zee PC. Self-reported short sleep duration and frequent snoring in pregnancy: impact on glucose metabolism. Am J Obstet Gynecol. 2010;203:142.e141-142. e145.

11. O'Brien LM, Bullough AS, Chames MC, et al. Hypertension, snoring, and obstructive sleep apnoea during pregnancy: a cohort study. BJOG. 2014;121:1685-1693.

12. O'Brien LM, Bullough AS, Owusu JT, et al. Pregnancy-onset habitual snoring, gestational hypertension, and preeclampsia: prospective cohort study. Am J Obstet Gynecol. 2012;207:487.e481-487. e489.

13. Louis JM, Koch MA, Reddy UM, et al. Predictors of sleep-disordered breathing in pregnancy. Am J Obstet Gynecol. 2018;218:521. e521-521.e512.

14. Bourjeily G, Raker CA, Chalhoub M, Miller MA. Pregnancy and fetal outcomes of symptoms of sleep-disordered breathing. Eur Respir J. 2010;36:849-855.

15. Na-rungsri $\mathrm{K}$, Lertmaharit $\mathrm{S}$, Lohsoonthorn $\mathrm{V}$, Totienchai $\mathrm{S}$, Jaimchariyatam N. Obstructive sleep apnea and the risk of preterm delivery. Sleep Breath. 2016;000:1-7.

16. Ko HS, Kim MY, Kim YH, et al. Obstructive sleep apnea screening and perinatal outcomes in Korean pregnant women. Arch Gynecol Obstet. 2013;287:429-433.

17. Antony K, Agrawal A, Arndt M, et al. Association of adverse perinatal outcomes with screening measures of obstructive sleep apnea. J Perinatol. 2014;34:441-448.

18. Köken G, Kir Sahin F, Cosar E, et al. Oxidative stress markers in pregnant women who snore and fetal outcome: a case control study. Acta Obstet Gynecol Scand. 2007;86:1317-1321.

19. Pamidi S, Pinto LM, Marc I, Benedetti A, Schwartzman K, Kimoff RJ. Maternal sleep-disordered breathing and adverse pregnancy outcomes: a systematic review and metaanalysis. Am J Obstet Gynecol. 2014;210:52.e51-52.e14

20. Louis J, Auckley D, Miladinovic B, et al. Perinatal outcomes associated with obstructive sleep apnea in obese pregnant women. Obstet Gynecol. 2012;120:1085-1092.

21. Maimon N, Hanly PJ. Does snoring intensity correlate with the severity of obstructive sleep apnea. J Clin Sleep Med. 2010;6:475-478.

22. Lee L-A, Yu J-F, Lo Y-L, et al. Energy types of snoring sounds in patients with obstructive sleep apnea syndrome: a preliminary observation. PLoS ONE. 2012;7:e53481.

23. Kim J-W, Lee $\mathrm{CH}$, Rhee CS, Mo J-H. Relationship between snoring intensity and severity of obstructive sleep apnea. Clin Exp Otorhinolaryngol. 2015;8:376-380.

24. Mitchell EM, Hinkle SN, Schisterman EF. It's about time: a survival approach to gestational weight gain and preterm delivery Epidemiology. 2016;27:182-187.

25. Parikh LI, Reddy UM, Mannisto T, et al. Neonatal outcomes in early term birth. Am J Obstet Gynecol. 2014;211:265.e261-265.e211.

26. Reddy U, Ko C-W, Willinger M. "Early" term births (37-38 weeks) are associated with increased mortality. Am J Obstet Gynecol. 2006;195:S202.
27. ACOG. ACOG Committee Opinion No 579: definition of term pregnancy. Obstet Gynecol. 2013;122:1139-1140.

28. Sarberg M, Svanborg E, Wiréhn A-B, Josefsson A. Snoring during pregnancy and its relation to sleepiness and pregnancy outcome-a prospective study. BMC Pregnancy Childbirth. 2014;14:15.

29. O'Brien LM, Bullough AS, Owusu JT, et al. Snoring during pregnancy and delivery outcomes: a cohort study. Sleep. 2013;36:1625.

30. Galal M, Symonds I, Murray H, Petraglia F, Smith R. Postterm pregnancy. Facts Views Vis ObGyn. 2012;4:175.

31. Bliwise DL, Nekich JC, Dement WC. Relative validity of selfreported snoring as a symptom of sleep apnea in a sleep clinic population. Chest. 1991;99:600-608.

32. Nieto FJ, Young TB, Lind BK, et al. Association of sleep-disordered breathing, sleep apnea, and hypertension in a large communitybased study. JAMA. 2000;283:1829-1836.

33. Gottlieb DJ, Yao Q, Redline S, Ali T, Mahowald MW. Does snoring predict sleepiness independently of apnea and hypopnea frequency? Am J Respir Crit Care Med. 2000;162:1512-1517.

34. Ben-Israel N, Tarasiuk A, Zigel Y. Obstructive apnea hypopnea index estimation by analysis of nocturnal snoring signals in adults. Sleep. 2012;35:1299-1305.

35. Herzog M, Schieb E, Bremert T, et al. Frequency analysis of snoring sounds during simulated and nocturnal snoring. Eur Arch Otorhinolaryngol. 2008;265:1553-1562.

36. Leung PL, Hui DSC, Leung TN, Yuen PM, Lau TK. Sleep disturbances in Chinese pregnant women. BJOG. 2005;112:1568-1571.

37. Gargano JW, Holzman C, Senagore P, et al. Mid-pregnancy circulating cytokine levels, histologic chorioamnionitis and spontaneous preterm birth. J Reprod Immunol. 2008;79:100-110.

38. Lavie L. Oxidative stress inflammation and endothelial dysfunction in obstructive sleep apnea. Front Biosci (Elite edition). 2011;4:1391-1403.

39. Okun ML, Roberts JM, Marsland AL, Hall M. How disturbed sleep may be a risk factor for adverse pregnancy outcomes a hypothesis. Obstet Gynecol Surv. 2009;64:273.

40. Edwards N, Sullivan CE. Sleep-disordered breathing in pregnancy. Sleep Med Clin. 2008;3:81-95.

41. Morgan TK. Role of the placenta in preterm birth: a review. Am J Perinatol. 2016;33:258-266.

\section{SUPPORTING INFORMATION}

Additional supporting information may be found online in the Supporting Information section at the end of the article.

How to cite this article: Dunietz GL, Shedden K, Schisterman EF, Lisabeth LD, Treadwell MC, O'Brien LM. Associations of snoring frequency and intensity in pregnancy with time-todelivery. Paediatr Perinat Epidemiol. 2018;32:504-511. https:// doi.org/10.1111/ppe.12511 